\title{
STUDY ON DETERIORATION OF HISTORIC MASONRY IN THE FORBIDDEN CITY IN BEIJING AIDED BY GIS
}

\author{
Tianyue Qin ${ }^{1}$, Haochuan Yu ${ }^{1}$, Shibing Dai ${ }^{1,2}$, Peng Zhang ${ }^{1}$ * \\ ${ }^{1}$ Dept. of Architecture, College of Architecture and Urban Planning, Tongji University, 1239 Siping Road, Shanghai, P.R. China - \\ ada q@tongji.edu.cn, 541894374@qq.com, daishibing@tongji.edu.cn, zhangpeng.patrick@qq.com \\ ${ }^{2}$ Architectural Conservation Laboratory, Tongji University, 1239 Siping Road, Shanghai, P.R. China
}

KEY WORDS: ArcGIS, Forbidden City, Historic Masonry, Deterioration.

\begin{abstract}
:
The Forbidden city in Beijing is one of the first culture heritage to be listed as UNESCO World Heritage in 1987. The mass and complexity of this imperial palace brings challenges to scientific surveys and documentations. This graduation project adopted the technology of GIS to record, evaluate and analyze historic masonry and their deteriorations across the palace. Aided by ArcGIS, the deterioration degree of every accessible masonry element was accurately and efficiently evaluated and recorded, as well as connected to its precise location among the Forbidden City. All accessible masonry elements in Forbidden City were divided into different types as buildings, walls, foundations, and stairs. The common deteriorations of masonry in Forbidden City were defined and graded according to their degree of severity so that the deterioration was quantified, and a database was established. Before the survey, the mechanism of masonry deterioration in the Forbidden City was presumed to be related to several possible factors. Adopting ArcGIS to set up a database enabled to visualize the distribution of masonry deterioration in the site and lead to a preliminary conclusion, as well as a further mathematic analysis of the data to better understand the cause of deterioration.
\end{abstract}

\section{RESEARCH BACKGROUND}

\subsection{General Introduction}

The Forbidden City in Beijing is one of the most important architectural heritage sites in China with unique culture connotations. The importance to record and study deteriorations of historic masonry in the Forbidden City is beyond doubt.

The Forbidden City in Beijing, the imperial palace of Ming and Qing Dynasties in China, also currently known as the Forbidden City, locates in the center of Beijing's central axis. It was built in 1406 based on the Forbidden City in Nanjing and the construction completed in 1420. Being the essence of China's ancient palace architecture, the Forbidden City is a rectangular city, 961 meters long from north to south, 753 meters wide from east to west, surrounded by a 10-meter-high wall, and a 52meter-wide fosse outside. With three main halls as its core, the complex covers an area of 720,000 square meters and a construction area of about 150,000 square meters, containing over 70 palaces and 9000 houses (Figure 1). The Forbidden City in Beijing is one of the largest and best-preserved heritage sites in the world.

The Forbidden City, with its dual status of national monument and world heritage, is the highest-level architectural heritage in China. Masonry is an important material type of the Forbidden City, thus the research on the deterioration of masonry and its distribution is of great significance for the conservation of this important heritage site.

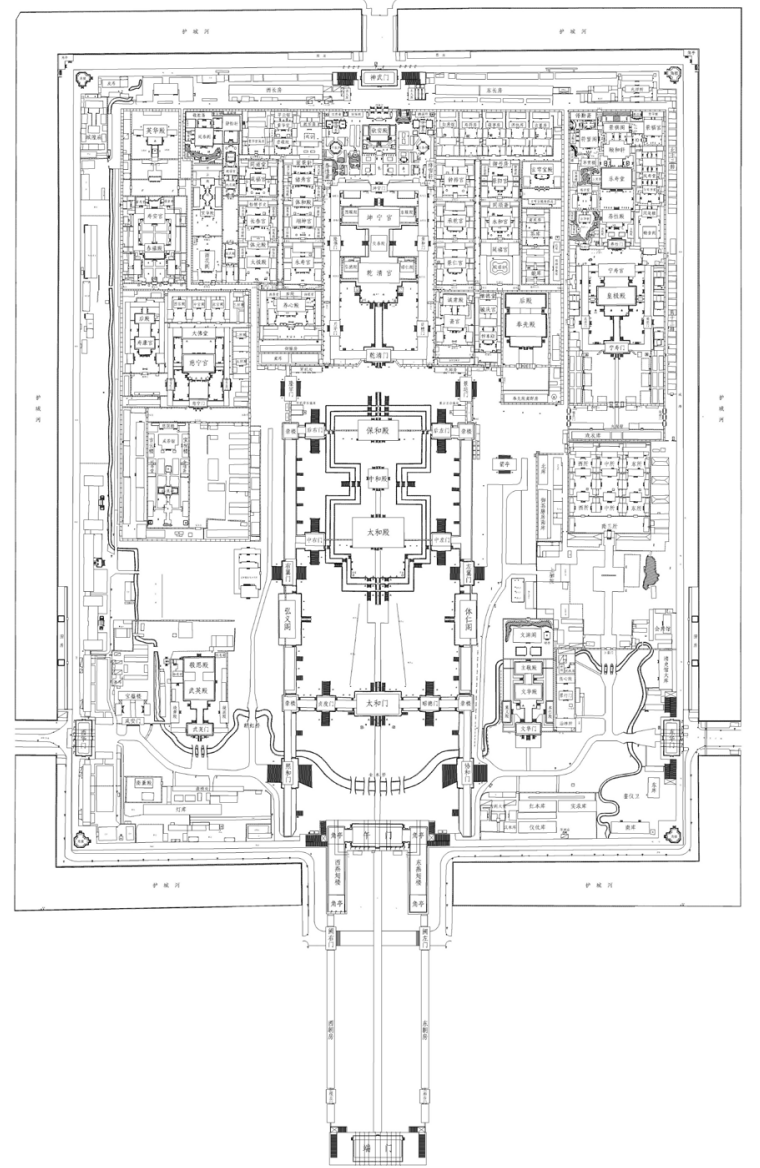

Figure 1. Plan of the Forbidden City in Beijing.

\footnotetext{
* Corresponding author
} 


\subsection{Problem Analysis}

There are some flaws in the traditional recording, protection, and research mode of masonry in the Forbidden City. It is recorded in a memorial in August of the 15th year of Guangxu (1889), "in front of the Taihe Palace, of the upper part of Danbi (steps leading up to the imperial palace), on the north of west stamp, one balustrade, one pillar, and one drum were injured and broken." (Figure 2). According to the literature, the typical ways of describing the deterioration of masonry in Qing Dynasty includes the location of masonry ("the north side of Danbi" \& "on the north of west stamp"), the name and quantity of components ("one balustrade"), and the name of deteriorations ("injured and broken"). On the other hand, the deteriorations of masonry were named in Qing Dynasty, such as broken, wronged, collapsed, crooked, flashed, crispy salt and so on. However, this kind of recording method is still primitive and inaccurate. Due to the high generalization of the text and the lack of image evidence, the specific deterioration type and degree of masonry cannot be judged.

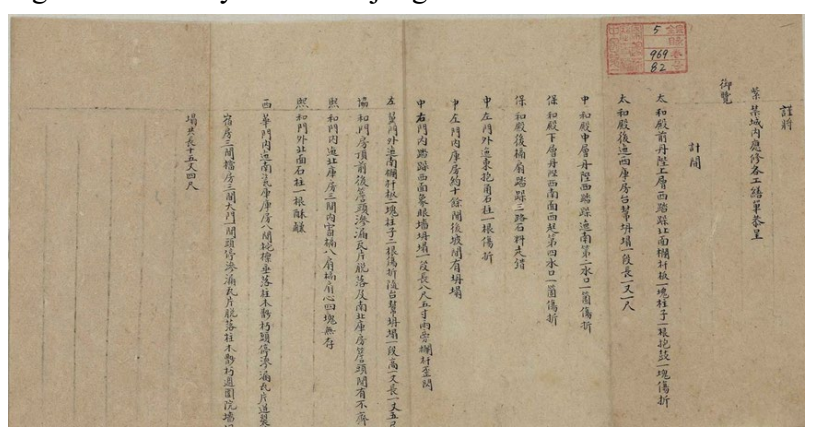

Figure 2. A memorial in 1889 that described the deterioration of several parts near Taihe Palace.

The current domestic research on historic masonry can be mainly divided into two types. One is the research on shape and structure, such as Liu Dake's "Construction Laws of Tiles and Stone in Ancient Chinese Buildings", which introduces in detail the construction methods of masonry in Ming and Qing official buildings. The other type is the technical research on the characteristics and deteriorations of masonry. In "Research and Application on the Protection of Stone Structure of historic buildings in Beijing", detailed data collection is carried out on the characteristics and deteriorations of stone in historic buildings in Beijing. Since the last century, the conservation of bricks in the Forbidden City has gradually got attention in domestic academic circles (Jiang J., 1997 \& Zhen G., 2004), while not much research on the stone material on the cultural relics inside the Forbidden City is found. The article "Evaluation and Research on the Conservation of Stone Cultural Relics in Jianfu Palace of the Forbidden City" carried out quantitative tests on the condition of stone cultural relics in Jianfu Palace area but lacked detailed pathological analysis and constructive protection proposals (Qu L., 2012).

Therefore, there are following problems in the current research on the masonry in the Forbidden City:

1) There is a lack of research on the overall conditions of masonry in the Forbidden City.

2) The studies of architectural form and structure have been completely separated from the study of materials' characteristics and deteriorations.
3) The research on material-level structure is mainly based on words, lacking illustrations.

4) The definitions of deteriorations are inaccurate, and the classification descriptions are confusing.

\subsection{Why GIS}

The application of modern scientific and technological methods in the conservation of historic buildings is becoming more and more mature. Adopting the technology of GIS to record and analyze the masonry in the Forbidden City has great advantages.

With the continuous development of science and technology, the conservation and recording methods of historic buildings has gradually become different from the traditional mode of manual surveying and mapping. In recent years, threedimensional laser scanning, UAV photogrammetry, VR panoramic roaming and other methods have been widely used in the recording of a single historic building. Aside from the advanced methods above, the most important step for surveying the large-scale architecture complex is to establish the relationship between the single buildings and the overall layout. Therefore, GIS was chosen as the main tool for documentation and analysis with illustrations. The advantages mainly include following:

1) The database required by ArcGIS provides a framework for the detailed documentation on conditions of historic masonry in the Forbidden City.

2) The information of each single architectural element can be related to its precise location in the layout of the architecture complex through the plan.

3) A large amount of information can be expressed directly and visually in the illustrations generated by ArcGIS, which helps to summarize the overall condition, distribution and finally the mechanism of masonry deteriorations in the Forbidden City.

\section{STUDY OBJECT}

\subsection{Range of Study}

The range of this research was the whole accessible area of Forbidden City, including all open tourist areas and some of the office areas. The city walls surrounding the Forbidden City were excluded, for 1) the city walls can be considered as a relatively independent monument rather than common masonry, and 2) there had already been detailed studies on the city walls. The bricks as floor tiles were also excluded because of its mass and the difficulty of completing the survey in several weeks. Since the research area was large, the whole Forbidden City was divided into several architecture groups, and the research was conducted group by group. The main architecture groups are: Huangji Palace and Ningshouquan Palace group, East Six Palace group, West Six Palace group, Qianqing Palace group, Cining Palace and Shoukang Palace group, Taihe Palace group, Wenhua Palace group, Luanyiwei warehouse area, city walls and watchtowers group (Figure 3). Though there were many inaccessible areas due to various reasons in Spring 2019, efforts were made to guarantee that the survey would cover as much open areas of the Forbidden City as possible. 


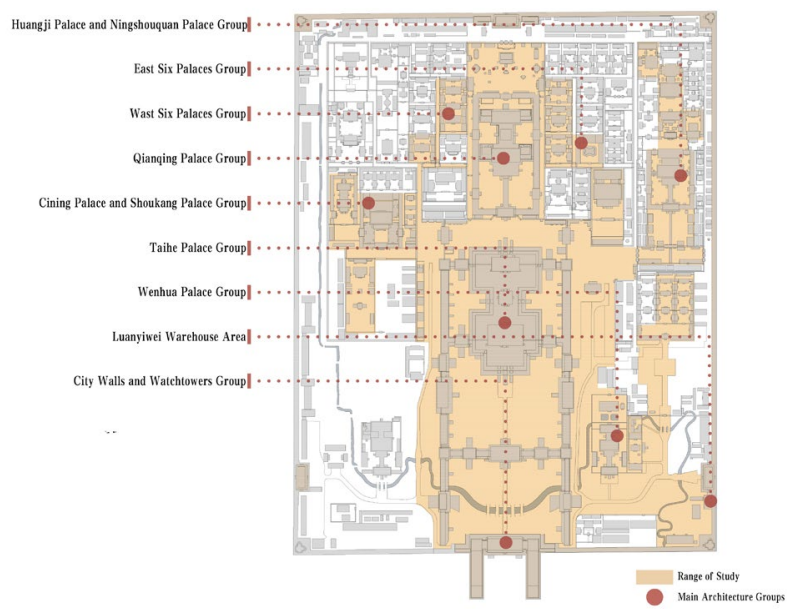

Figure 3. Main architecture groups, divided to better conduct the field survey.

\subsection{Study Object}

The masonry, especially the characteristics and deteriorations of its material is the main study object of this project. There are mainly two kinds of stone in the Forbidden City: white marble and bluish white stone. The main components of these two kinds of stones are dolomite $\left(\mathrm{CaCO}_{3}\right.$ and $\left.\mathrm{MgCO}_{3}\right)$. The white marble (Hanbaiyu) is of high purity and contains less mica, quartz, and other impurities, thus is whiter in color but softer in texture, so that it is mostly used for decorative components and parts such as outdoor balustrades, columns and Danbis. The bluish white stone (Qingbai Stone) contains more impurities and some carbonaceous materials. Its color is slightly bluish gray, and its strength is higher than that of white marble. Therefore, it is often used in bearing positions such as corner stones of buildings, steep slabs of Foundation foundations, stair steps, and Xiangyan (sides of steps).

The bricks in the masonry of the Forbidden City are mainly grey bricks made of clay, with $\mathrm{SiO}_{2}, \mathrm{FeO}, \mathrm{Fe}_{3} \mathrm{O}_{4}$, etc. as main chemical components. The strength of grey bricks adopted is high, so the main positions using grey bricks include walls, city walls, outdoor ground tiles, etc. Because of its high porosity and great ability to absorb water, grey bricks in historic masonry in the Forbidden City are greatly influenced by the outdoor environment and tourists and show a large degree of deterioration. The research on the deterioration and preservation in this project will mainly focus on the grey bricks used on the facade walls, and Foundations of the buildings in the Forbidden City. Some mortar in the Forbidden City was also recorded.

\section{METHODOLOGY}

\subsection{Technical Route}

The technical route of this project is a complete structure consisting of three parts. Firstly, the problems were found through data-processing aided by ArcGIS at the macro level, including classification of architectural elements, the definition and classification standards of deteriorations, data collection and analysis. After that, the problems were summarized and analyzed through the survey on structure and deterioration in the meso level. Finally, the problem was solved through the conservation experiments of stone and brick at the micro level. Step by step, the three steps correspond to the three stages of the research and together form the whole research content (Figure 4).

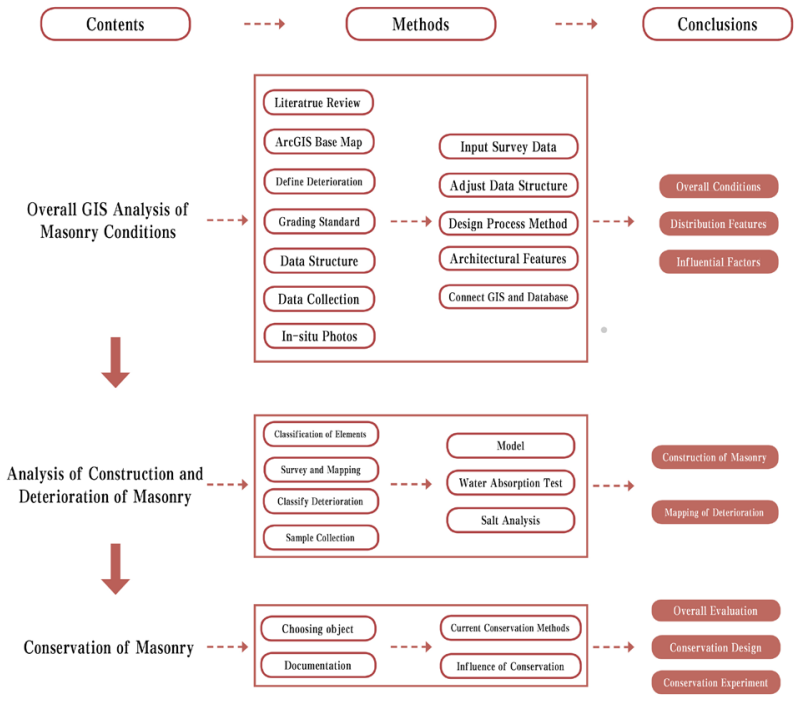

Figure 4. Technical route of the project.

\subsection{Classification of Architectural Elements}

In an architecture group, the architectural elements of historic buildings were divided into four categories: Building, Wall, Foundation, and Staircase (Figure 5).
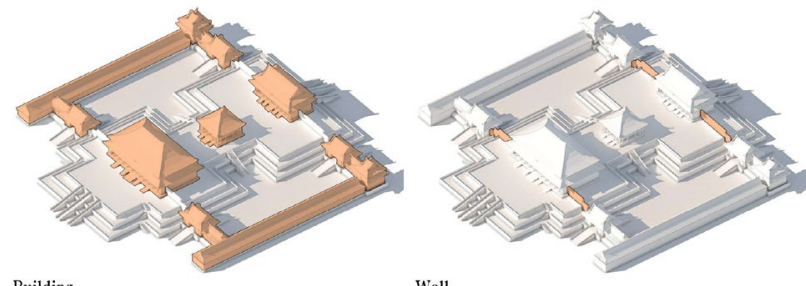

Building

Wall
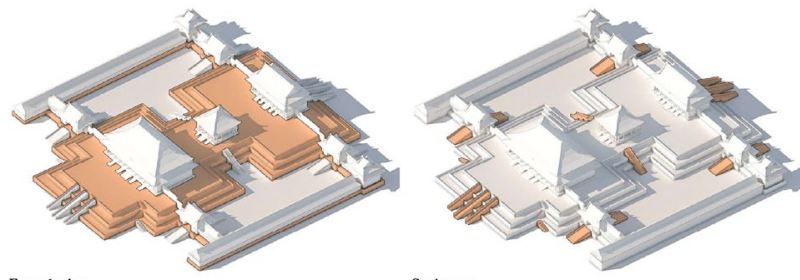

Figure 5. Four Categories of architectural elements in Taihe Palace group.

Building is the most important part of the architecture group. To simplify the study objects, the Foundation, steps, and other subsidiary parts of the architecture group itself are included in the Building category. Taking the Taihe Palace Group as an example, the Building category includes three palaces themselves and the surrounding verandas, doors, Chong buildings, as well as the building's own Foundation and steps.

Walls mainly plays the role of enclosure and separation in the composition of the architecture group. The Wall category only includes walls independent of buildings, such as palace walls and courtyard walls. In the architecture group of Taihe Palace, the Wall mainly refers to the walls on both sides of the palace.

Most foundations in the Forbidden City are associated with buildings, and some important buildings have smaller foundations within their cornice projection lines. In the Foundation category, large-scale foundations were investigated, most of which are shared by multiple buildings in the group. In 
the Taihe Palace group, the Foundation category mainly includes the foundation of the three main palaces and the foundation connecting the side halls, verandas, and other affiliated buildings.

There are mainly two kinds of staircases in the building group: the staircases connecting the foundation and the ground, and the staircases between the two foundations or between the building and the foundation. Due to the large amount and small scale of the latter ones, the first kind of staircases were listed as the main study objects in the field survey to the Staircase category. In the Taihe Palace complex, the Staircase category mainly included the large-scale staircases around the foundation.

\subsection{Deterioration Definition and Classification Standard}

According to the current national stone heritage deterioration standards and in-situ observation and summary, six kinds of basic deteriorations of brick and stone were listed separately. Each deterioration was divided into four levels according to the severity.

\begin{tabular}{|c|c|c|c|}
\hline \multicolumn{2}{|c|}{ Stone } & \multicolumn{2}{c|}{ Brick } \\
\hline Number & Deterioration & Number & Deterioration \\
\hline 1 & Dirt & 1 & Detachment \\
\hline 2 & Peeling & 2 & Peeling \\
\hline 3 & Cracking & 3 & Cracking \\
\hline 4 & Powdering & 4 & Powdering \\
\hline 5 & Discolor & 5 & Discolor \\
\hline 6 & Plant & 6 & Efflorescence \\
\hline
\end{tabular}

Table 1. Masonry deteriorations category in the Forbidden City.

\subsection{Data Collection}

To get enough data that could be later processed and analyzed, a series of data collection methods were designed for every architectural element. Taking the Taihe Palace as an example, in addition to the basic information such as the width, depth and height of the building, the height and depth of cornice, height difference between indoor and outdoor and other factors that might be related to the deteriorations were also recorded. At the same time, the deterioration condition of five orientations (east, west, south, north and ground) of a single architectural element were rated and recorded in detail. To ensure the unification of grading standards, students who collected the data discussed with the instructors after everyday research to increase the authenticity of the collected data.

Finally, a table for data collection was designed to input the data later conveniently into the GIS database (Table 2). During the whole field survey, more than 750 architectural elements were investigated. For each element, more than 60 data was recorded. These data were later used as the basis of GIS analysis (Table 3).

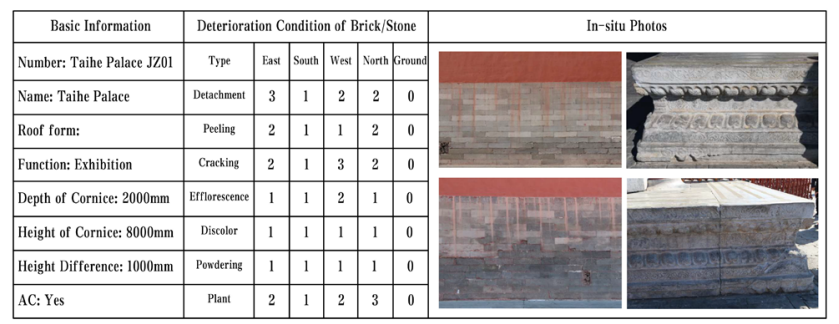

P.S. The grades from 1 to 4 refers to the increasing degree of deterioration, and 0 indicates that there is no corresponding material (brick or stone) in
this direction.

Table 2. Table designed for data collection.

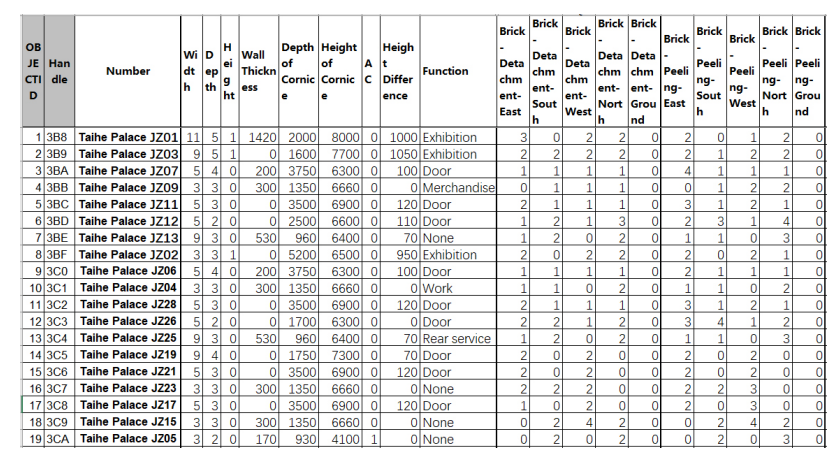

Table 3. ArcGIS database (partial).

\section{DATA ANALYSIS AND RESULTS}

\subsection{State and Distribution of Deterioration}

In this part, the original data of elements was simply processed to evaluate the state and distribution of different deteriorations. Factors such as replacement-repair and location were introduced to preliminarily analyze the reason of deterioration based on the visual comparison between ArcGIS images.

\subsubsection{Overall Deterioration Condition}

First, the comprehensive deterioration condition of brick and stone were analyzed. Every deterioration in the east, south, west, north, and ground of each architectural element was recorded and rated. Through the data, the comprehensive deterioration in each direction of each element was evaluated. To illustrate the overall deterioration condition of both brick and stone, the average deterioration condition and the most serious deterioration condition of each direction was both taken into consideration (Figure 6). Further obtained was the overall deterioration condition of masonry through the "mean + maximum" data processing method. That is, to calculate the mean value of all directions and then plus the biggest number of all directions, so that the overall deterioration condition could be reflected (Figure 7).

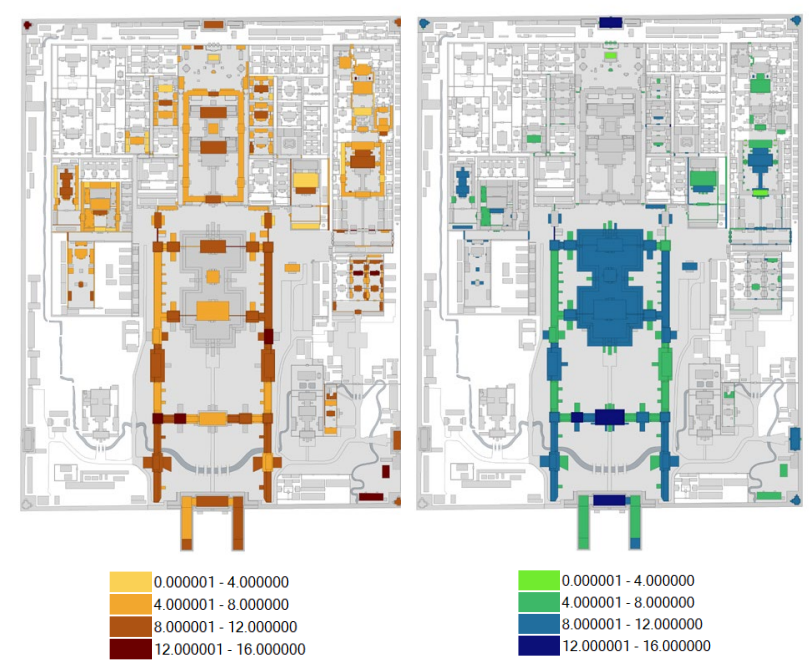

Figure 6. The overall deterioration condition of brick (left) and stone (right). 


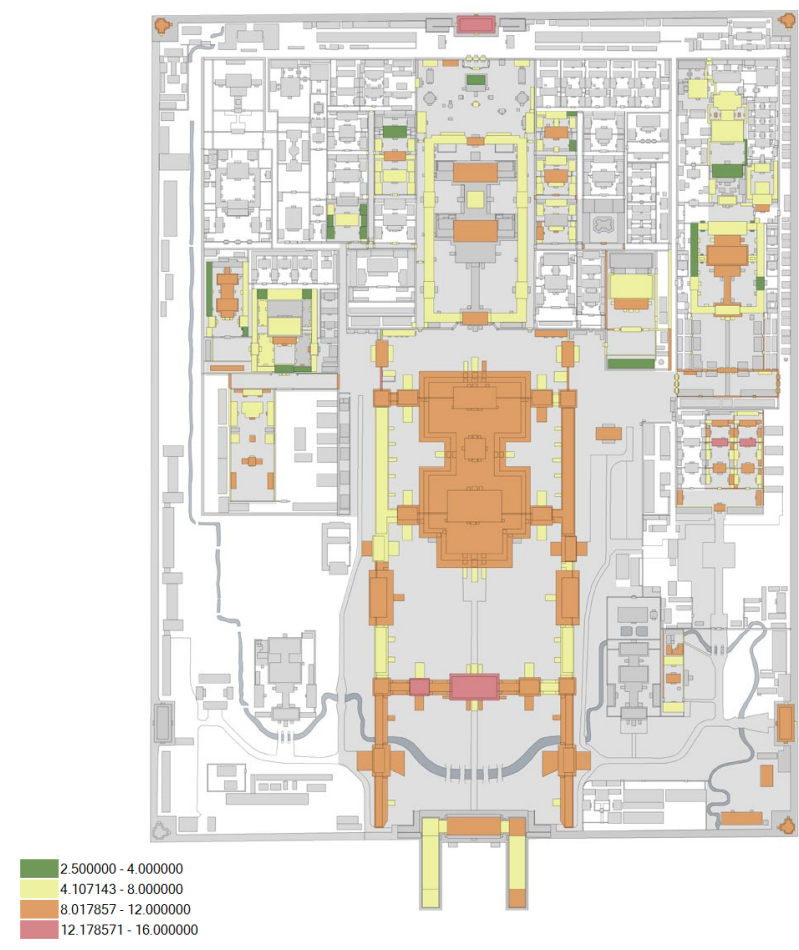

Figure 7. The overall deterioration condition of masonry.

\subsubsection{Distribution of Deteriorations}

The distribution of every deterioration of brick and stone was analyzed (see Appendix). The processing method of original data was also the "mean + maximum" method. Taking the peeling of brick as an example: the grading of Taihe Palace JZ01's five orientations is $(3,0,2,2,0)$, so the result of its peeling grading would be $(3+2+2) / 3+3=5.333$. 16 illustrations were generated to visually reflect the deterioration conditions of brick and stone.

\subsubsection{Replacement and Repair}

During the process of investigation, it was found that replacement and repair had a great impact on the deterioration of stone, so not only the deterioration was recorded, but also the replacement and repair status of every single façade was evaluated (Table 3 ).

\begin{tabular}{|c|c|c|c|}
\hline Deterioration & Definition & Grade & Description \\
\hline \multirow{4}{*}{$\begin{array}{l}\text { Replacement } \\
\text { and } \\
\text { Repair }\end{array}$} & \multirow{4}{*}{$\begin{array}{l}\text { Replacement } \\
\text { and repair of } \\
\text { the original } \\
\text { stone and } \\
\text { bricks in } \\
\text { masonry, if } \\
\text { visually } \\
\text { recognizable. }\end{array}$} & 1 & No repair. \\
\hline & & 2 & $\begin{array}{l}\text { Several small-scale } \\
\text { repairs, or the } \\
\text { proportion of the area } \\
\text { is less than or equal to } \\
25 \% \text {. }\end{array}$ \\
\hline & & 3 & $\begin{array}{l}\text { More small-scale } \\
\text { repairs or several } \\
\text { large-scale repairs, } \\
\text { with the proportion of } \\
\text { area less than } 50 \% \text {. }\end{array}$ \\
\hline & & 4 & $\begin{array}{l}\text { Many large-scale } \\
\text { repairs, or the } \\
\text { proportion of area is } \\
\text { more than } 50 \% \text {. }\end{array}$ \\
\hline
\end{tabular}

Table 3. Definition and grading standards of replacement and repair.

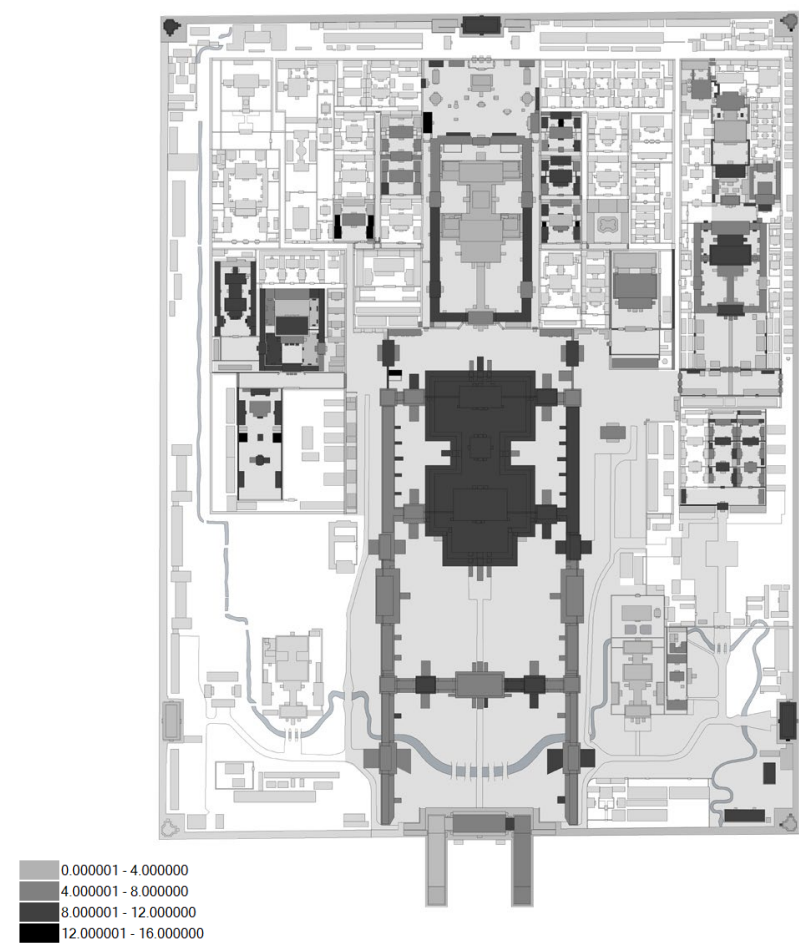

Figure 8. The replacement-repair condition of masonry.

The overall deterioration condition was compared with replacement-repair condition (Figure 8). It was found that the replacement-repair is more common in the location with more serious deterioration, showing a state of "the worse the deterioration, the more the repair, yet the more the repair, the worse the deterioration". The result might indicate that current repair methods of masonry in the Forbidden City have flaws. Among them, the deterioration and replacement-repair degree of the central axis buildings were relatively high, which may lead to serious deterioration due to the large pedestrian flow of the central axis buildings. Another factor might be the fact that the repair of the central axis buildings started earlier, and the deterioration accumulation time was longer.

\subsubsection{Influence of Location}

The overall deterioration illustrations showed that the distribution of masonry deteriorations in large-scale building location may have certain patterns. The collation of these patterns would help to further analyze the influence of building location and deterioration distribution. The focus of location analysis was the basic trend of distribution, and conjectures about the causes of this trend were raised.

Jinshui River may be one of the factors affecting the distribution of deteriorations. Within the range of investigation, the deterioration gradings of buildings around Jinshui River were generally 3 or higher. The influence of Jinshui River on the buildings may lie in the evaporation of water and the infiltration of groundwater. However, the buildings near Jinshui River were influenced by high foundations or courtyard walls, which will interfere with the judgment of the results.

Considering the Forbidden City as a whole, the deterioration of the buildings near the central axis was higher, and the deterioration degree of the buildings on both sides of the main 
axis was lower. There was a trend that the deterioration degree of the southern building complex is higher than that of the north.

Within a single architecture group, the deteriorations of main buildings were relatively high, while the deteriorations of affiliated buildings such as the side halls and verandas were relatively low. The overall deterioration of the main axis of the building was more serious, which may be related to the sequence of renovation. In architecture groups, the side halls were generally used for office, commercial and other functions, and the repair of these buildings might be more frequent than the main buildings.

\subsection{Deterioration and Orientation}

It was speculated that the orientation would also be a factor affecting the deterioration conditions of masonry. Since the disease conditions of each architectural elements in all four directions were recorded in the field survey, a comprehensive analysis of all deteriorations on each direction can be illustrated (Figure 9). The overall masonry deterioration condition of the south facade was the most serious. However, the overall distribution trends of diseases in each direction were similar.

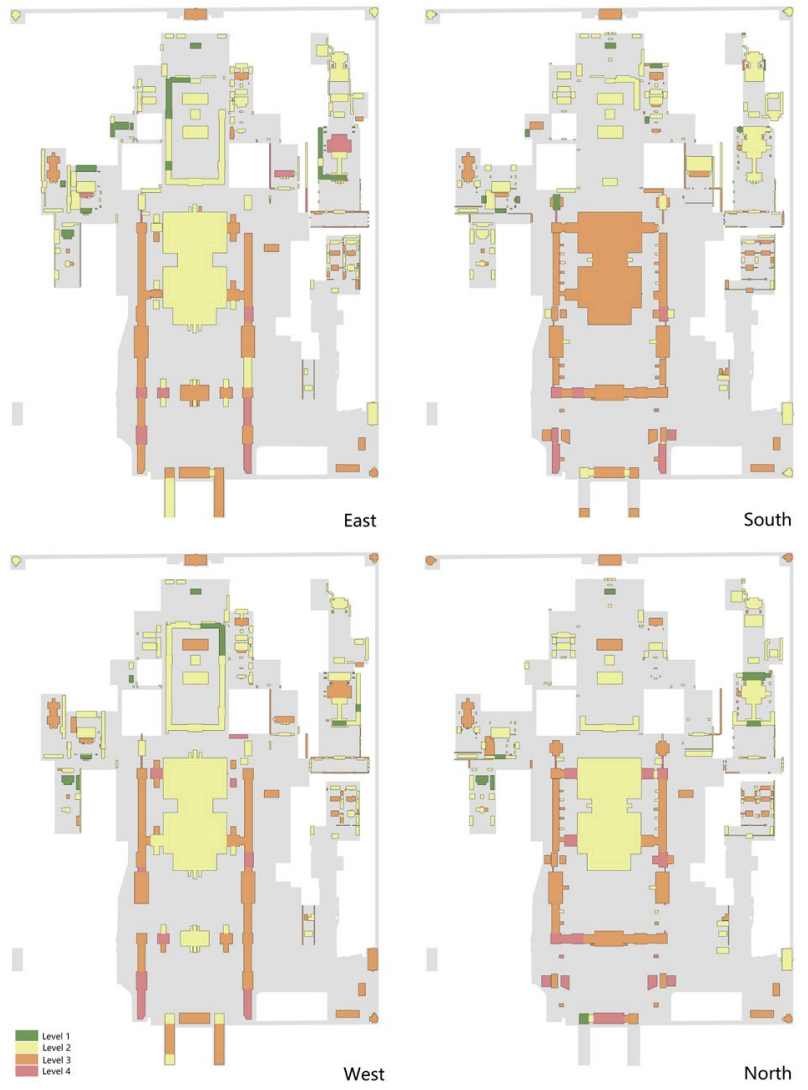

Figure 9. Overall deterioration conditions on 4 directions.

Furthermore, the original data can be analyzed by calculating the variance of deterioration grading on the 4 orientations of architectural elements, so that which deteriorations were most greatly affected by orientations could be figured out. After data processing and illustrations, the results indicated that the overall color of brick's powdering and efflorescence were the deepest, which indicated that the factor of orientation had the greatest impact on these two deteriorations. However, the influence of orientation on different deteriorations of bricks appeared to be little. For stone, discolor and cracking were the two deteriorations most influenced by the factor of orientation.

\subsection{Deterioration and Architectural Features}

\subsubsection{Architectural Features}

Some architectural features might be related to the degree of deteriorations, such as the cornices and height difference between indoor and outdoor ground. For buildings and walls, the characteristics of their cornices would affect the degree of deterioration. The cornice index was defined as the ratio of cornice height and depth, after which further research and analysis were conducted. The cornice height was the height from cornice to surface of foundation, and the cornice depth was the horizontal distance from cornice to masonry surface. The larger the cornice index is, the shallower the cornice is. On the contrary, the lower the cornice index is, the deeper the cornice is.

\subsubsection{Humidity Index}

The direct influence of cornice index and height difference on the architectural elements was reflected by their influence on humidity. Cornices affect buildings' contact with rainwater and sunshine, while the height difference is closely related to groundwater and rising damp. Therefore, the moisture index was introduced as an intermediate to reflect the impact of these two characteristics on the deterioration. Deteriorations related to humidity such as efflorescence, discolor and plant were selected and given different proportions (30\%-70\%), so that the value of humidity index could be calculated. Based on the data, the relationship between architectural features and humidity could be studied.

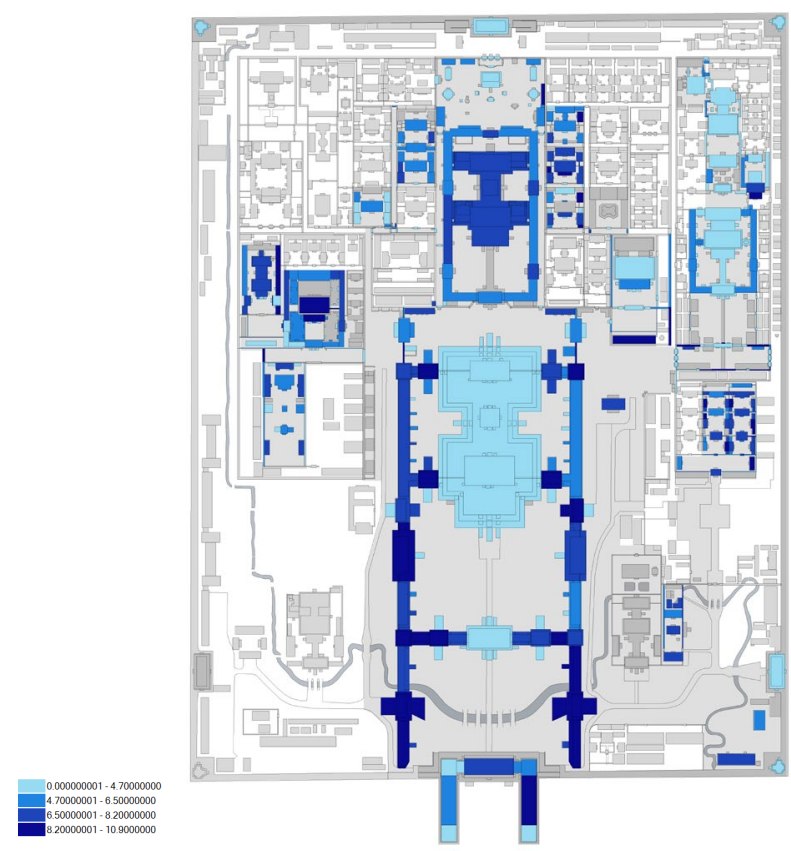

Figure 10. The distribution of humidity.

It was speculated that the smaller the cornice index was, the lower the humidity index might be, for deeper cornices could better protect the masonry from rainwater and sunshine. Buildings with higher foundations might be less humid, for another possible cause of humidity is the underground water, which can be stopped by the foundation. On the other hand, if buildings with lower foundations were proved to be drier, it may indicate that the source of humidity in the masonry of the Forbidden City is mainly from rainwater rather than rising damp. 
However, no obvious relationship was found between architectural features and humidity index according to the current data. Further research is needed to either confirm the theories above or prove them wrong.

\section{CONCLUSION AND DISCUSSION}

This project of survey, evaluation, and analysis of historic masonry in the Forbidden City aided by GIS provided the possibility to further study the deterioration mechanics of historic masonry from a comparative perspective rather than single case studies. The first part of analysis on the overall deterioration conditions of masonry helped to better understand the status of masonry in the Forbidden City, followed by the further processing of the data to explore the possible factors of masonry deteriorations. The overall study also laid a foundation for the following documentation and conservation studies of both historic stone (Figure 11) and brick.

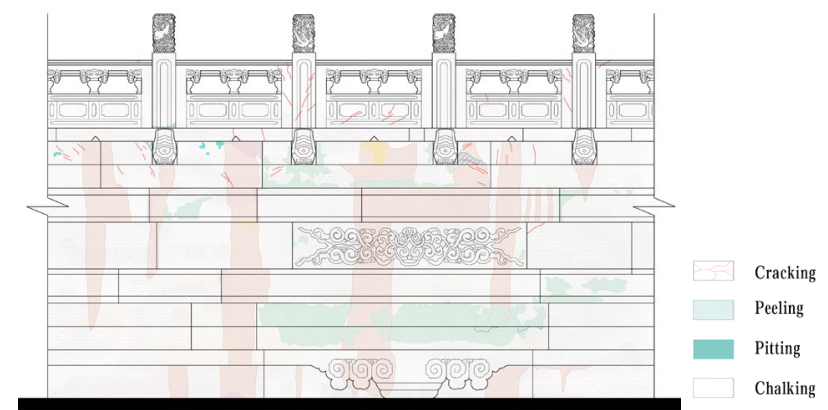

Figure 11. Mapping of stone deterioration of Taik $\ldots$ Crust foundation (partial). Scientific and quantitative recording and analysis $\square$ colouration masonry provided the possibility for the implems Repair preventive conservation. The foundation of Plant conservation is having fully understood the status of historic masonry, so that a monitoring system could be established, and appropriate conservation methods could be implemented. Regular evaluations on the status of historic masonry and the establishment of a database are needed.

In this project, data was collected through manuscripts and digitalized afterwards, which lead to repetitive work and possible mistakes. In recent years, advanced documentation methods and a brand-new tool system adopting mobile terminal research tools has been developed to survey historic buildings in large quantity (Liu K., 2019). This new survey method enables more accurate and efficient data collection process for architecture complex such as the Forbidden City. Further studies on the masonry in the Forbidden City would be strengthened if the digitalized tool system is adopted.

\section{ACKNOWLEDGEMENTS}

This contribution is based on the graduation project of Tianyue Qin and Haochuan Yu under the guidance of Professor Peng Zhang and Professor Dr. rer. nat. Shibing Dai. Both students were then undergraduates major in Conservation of Historic Architecture and now graduates major in Architecture of CAUP Tongji University. The Palace Museum and Peng Zhao, the head of The Department of Architectural Heritage are thanked for their support as well as Zhejiang DESAIBAO Ltd and Yue'e Zhou \& Faling Ju of the Architectural Conservation Laboratory of Tongji University, Shanghai.

\section{REFERENCES}

Beijing Institute of Ancient Architecture, 2018: Research and Application of Conservation of Stone Structure in Ancient Buildings in Beijing. Beijing: China Literature and History Press.

Jiang J., Li D., 1997: The Issue of Conservation of the Ancient Bricks in the Forbidden City. Proceedings of the Chinese Forbidden City Society, Volume 2, 1997:3.

Liu, K., Xue, Y., Zhao, D., Huang, Z., 2019: Study on the Survey, Identification Criteria and Tool System of Historical buildings Supported by the Technology of GIS. International Archives of the Photogrammetry, Remote Sensing and Spatial Information Sciences - ISPRS Archives, v42, n 2/W15, p 687694. doi.org/10.5194/isprs-archives-XLII-2-W15-687-2019.

National Cultural Heritage Administration of P.R. China, 2007: $W W / T$ 0002-2007, Classification and Legend on the Deterioration of Ancient Stone Objects.

National Cultural Heritage Administration of P.R. China, 2014: WW/T 0049-2014, Material for Maintenance and Conservation of Historic Architecture - Grey Brick.

Qu L., Zhu Y., Wang S., Lu S., 2012: Evaluation of the Conservation Condition of Stone Eelics in Jianfu Palace in the Forbidden City. Conservation of Cultural Relics and Science of Archaeology, 24(02), 6-13.

Zhen G., 2004: Studies on the conservation of bricks in the Forbidden City. Proceedings of the Symposium on the Conservation Technology of Brick and Stone Cultural Relics, 2004:10. 